in vivo $34: 213-223(2020)$

doi:10.21873/invivo. 11763

\title{
Expression of Podoplanin in Mammary Cancers in Female Dogs
}

\author{
PAULINA BORECKA ${ }^{1}$, RAFAL CIAPUTA ${ }^{1}$, IZABELA JANUS ${ }^{1}$, \\ ALEKSANDRA PIOTROWSKA ${ }^{2}$, KATARZYNA RATAJCZAK-WIELGOMAS ${ }^{2}$, ALICJA KMIECIK ${ }^{2}$, \\ MARZENA PODHORSKA-OKOLÓW ${ }^{3}$, PIOTR DZIĘGIEL $^{2,4}$ and MARCIN NOWAK ${ }^{1}$ \\ ${ }^{1}$ Department of Pathology, Division of Pathomorphology and Forensic Veterinary Medicine, \\ Wroclaw University of Environmental and Life Sciences, Wroclaw, Poland; \\ ${ }^{2}$ Department of Histology and Embryology, Wroclaw Medical University, Wroclaw, Poland; \\ ${ }^{3}$ Division of Ultrastructure Research, Wroclaw Medical University, Wroclaw, Poland; \\ ${ }^{4}$ Department of Physiotherapy, University School of Physical Education in Wroclaw, Wroclaw, Poland
}

\begin{abstract}
Background/Aim: Mammary neoplasms are very common tumours in female dogs. Cancer-associated fibroblasts $(C A F s)$ play an important role in the oncogenesis process. One of the useful proteins used in the diagnostics of CAFs cells is podoplanin (PDPN). The aim of our study was to assess the expression of PDPN in mammary cancer in female dogs. Materials and Methods: Our study cohort included 61 cancers and 21 adenomas of the mammary tumour in bitches. Expression of podoplanin, Ki-67 and HER2 was determined using the Immunohistochemical (IHC) method. PDPN expression at the mRNA level was determined using real-time PCR. Results: Expression of PDPN in CAFs was observed in $22.9 \%$ of cases of mammary cancers in bitches, with no PDPN expression in adenomas. A positive correlation was found between the expression of PDPN in $C A F s$ and the grade of histological malignancy and expression of Ki-67. Conclusion: PDPN plays a significant role during the process of carcinogenesis of mammary tumours in female dogs.
\end{abstract}

Cancer in the form of mammary tumours represents one of the most common oncological lesions in dogs (bitches). They are found mainly in the form of malignant lesions (cancers), and much less frequently in the form of benign lesions

This article is freely accessible online.

Correspondence to: Paulina Borecka, Department of Pathology, Division of Pathomorphology and Forensic Veterinary Medicine, Wroclaw University of Environmental and Life Sciences, Wroclaw, Poland. Tel: +48 71320 5444, e-mail: Paulina.borecka@upwr.edu.pl

Key Words: Podoplanin, PDPN, CAFs, mammary tumour, adenoma, female dog. (adenomas) (1-5). In the majority of bitches, the cancer process occurs in older animals and is located in the caudal ventral and inguinal region of the mammary ridge (1-4). The most commonly used diagnostic methods are i) biopsy and ii) histopathological examination following mastectomy. The final prognosis is based on the diagnosis of the type of tumour and the degree of histological malignancy, while in doubtful cases immunohistochemical (IHC) tests are used $(4,6)$.

Most published research focuses on assessing the type of cancer cells in order to determine the malignancy of the lesion and the prognosis for the patient (7-11). Following the trends in human medicine, more and more attention is also directed towards the analysis of the cancerous stroma, whose elements are, among others, the so-called cancer-associated fibroblasts (CAFs). CAFs are part of the stroma of many types of cancers, and their presence in breast cancer in women has been confirmed in many scientific reports (1215). The origin of CAFs is not yet fully understood, however, it is believed that these cells may originate from local fibroblasts, modified epithelial cells, bone marrow stem cells or cells undergoing epithelial-mesenchymal transition (EMT), and, according to recent reports, from local adipocytes (1618). It has also been reported that CAFs present in breast cancers show differences in functions as well as in gene expression compared to typical fibroblasts found in the body (13-14, 19). Moreover, CAFs in the tumour microenvironment affect the tumour development and its metastatic potential. This is due to the ability of CAFs to secrete many different cytokines, including epidermal growth factor (EGF), stromal cell-derived factor-1 (SDF-1), transforming growth factor $\beta$ (TGF- $\beta$ ), hepatocyte growth factor (HGF), and vascular endothelial growth factor A (VEGF A) (13, 20-25). In addition, CAFs modify and influence extracellular matrix proteins (ECM), which leads to changes in signaling between cancer cells $(21,26)$. 

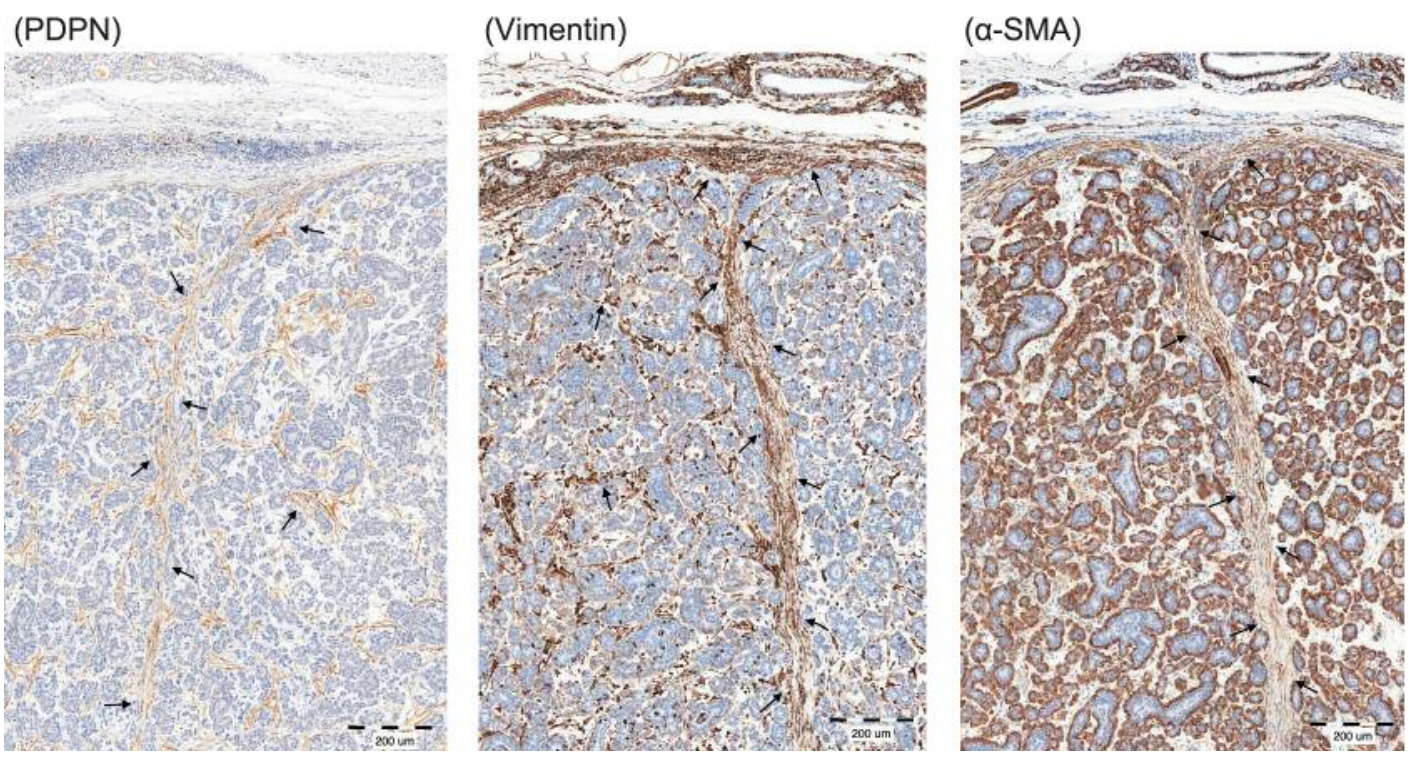

Figure 1. Serial sections: expression of podoplanin (PDPN), vimentin and $\alpha$-SMA in cancer-associated fibroblasts (CAFs) in mammary tumours in bitches. Scale bars $=200 \mu \mathrm{m}$.

Due to the involvement of CAFs in the process of carcinogenesis, as well as in the prognosis of patients, it is important to demonstrate their presence in the tumour $(12,15$, 20). Many cell markers aiding in the visualization of CAFs have been described in the literature. For example, Shoppmann et al., (27) have demonstrated the presence of CAFs in esophageal adenocarcinoma by using antibodies against alpha smooth muscle actin ( $\alpha$-SMA) and vimentin (27). Both of these markers are also used to diagnose and evaluate CAFs in IDC (invasive ductal carcinoma) in women (12-15, 20).

Recent studies have shown the presence of a protein called podoplanin (PDPN) in CAFs found in the stroma of breast cancer $(12-15,20,28)$. PDPN is an O-sialoglycoprotein made of 162 transmembrane amino acids (O-glycosylated sialoglycoprotein), which has many names in the literature, including gp36, gp38, T1alfa, Aggrus, OTS-8, PA2.26, M2A (13, 14, 20, 29, 35). This protein was discovered in 1990 in mouse osteoblastic cells lines (MC3T-E1) and in ras-transformed MC3T3 cells $(26,29)$. In studies carried out by BreitenederGeleff et al., PDPN expression has been shown in lymphatic endothelial cells of both malignant tumours (angiosarcoma) and benign hemangiomas and lymphangiomas (31). PDPN is also recognized as a selective marker of lymphatic vessel endothelium and it is not expressed in blood vessels (31). In addition, Breiteneder-Geleff et al., have been the first to show the expression of the discussed protein in podocytes in rats, and since then it has the name podoplanin (32). In the following years, PDPN found application in the diagnosis of cancer of skin, lungs, mammary glands, liver, bladder and esophagus (12-
Table I. Modified semi-quantitative scale (IRS- immunoreactive score) (42).

\begin{tabular}{lcc}
\hline Points & $\begin{array}{c}\text { A-Percentage of cells that } \\
\text { show positive reaction }\end{array}$ & $\begin{array}{c}\text { B-Color reaction } \\
\text { intensity }\end{array}$ \\
\hline 0 & $0 \%$ & No reaction \\
1 & $1-10 \%$ & Weak reaction \\
2 & $11-50 \%$ & Moderate reaction \\
3 & $51-80 \%$ & Intense and strong reaction \\
4 & $81-100 \%$ & \\
\hline
\end{tabular}

The results correspond to those shown in Figure 1. AUC: Area under the curve; CI: confidence interval.

$16,20,21,27,30,33)$. In the case of breast cancer in women, PDPN expression has been observed both in myoepithelial cells surrounding the glandular structures and in the cytoplasm of some cancer cells, as well as in CAFs $(12,14,15,20,27,31$, 34). Recent reports have shown that PDPN increases the migration of human fibroblasts and affects the structure of endothelial cells (28). Moreover, a positive relationship has been identified between the level of PDPN expression in CAFs and the grade of histological malignancy of the cancer, Ki-67, HER2 expression, tumour size, and the number of metastases to nearby lymph nodes $(12,14,15,20,28)$. Finally, patients with breast cancer who had high expression of podoplanin in CAFs appear to have significantly shorter survival times [overall survival (OS)] $(13,14,27,28,33)$. 
Table II. Assessment of podoplanin (PDPN) expression in cancer-associated fibroblasts (CAFs) and cancer cells, Ki-67, HER2 receptor in mammary tumours in bitches using previously described scales. Results rounded to full numbers. Expression intensities of studied markers grouped and encoded according to established assessment scales.

\begin{tabular}{|c|c|c|c|c|}
\hline & PDPN in CAFs & PDPN in cancer cells & $\mathrm{Ki}-67$ & HER2 \\
\hline & \multicolumn{4}{|c|}{$\begin{array}{l}\text { Malignant tumour, } \mathrm{n}(\%) \\
\mathrm{n}=61\end{array}$} \\
\hline None $(-)$ & $47(77)$ & $35(57.5)$ & $6(10)$ & $4(6,5)$ \\
\hline Weak (+) & $11(18)$ & $11(18)$ & $15(24.5)$ & $7(11.5)$ \\
\hline Moderate (++) & $0(0)$ & $8(13)$ & $22(36)$ & $10(16)$ \\
\hline \multirow[t]{2}{*}{ Intense $(+++)$} & $3(5)$ & $7(11.5)$ & $18(29.5)$ & $40(66)$ \\
\hline & \multicolumn{4}{|c|}{$\begin{array}{l}\text { Benign tumour, } \mathrm{n}(\%) \\
\mathrm{n}=21\end{array}$} \\
\hline None (-) & $21(100)$ & $14(67)$ & $20(95)$ & $1(5)$ \\
\hline Weak (+) & $0(0)$ & $6(28)$ & $1(5)$ & $5(24)$ \\
\hline Moderate (++) & $0(0)$ & $1(5)$ & $0(0)$ & $8(38)$ \\
\hline Intense $(+++)$ & $0(0)$ & $0(0)$ & $0(0)$ & $7(33)$ \\
\hline
\end{tabular}

Due to the common living environment and the incidence of the discussed cancerous lesions in both humans and animals, as well as the great similarity between the mammary gland of the woman and the mammary gland of the dog, both in its histological structure and function, we can assume that mammary cancer in dogs is a potentially promising model for human breast cancer (35). The aim of our work was to determine the level of PDPN expression intensity in both CAFs and cancer cells in mammary cancers and adenomas in female dogs, and to determine the relationship of its expression level and the patient's breed, age, tumour histological grade $(\mathrm{G})$ and expression of other cell markers connected with carcinogenesis such as HER2 and Ki-67. In addition, the co-localization of $\alpha$ SMA, vimentin and podoplanin expressions in CAFs in serial sections was determined to verify and confirm the type and location of fibroblast cells. These are the first such studies analyzing the level of podoplanin expression in mammary cancers in dogs conducted on such a large number of cases.

\section{Materials and Methods}

Patients and tumours/Population study. Immunohistochemical (IHC) tests were performed in 82 mammary gland tumour samples (61 cancers and 21 adenomas) collected from bitches of different breeds and ages. bitches (range $=6-14$ years).

The samples were obtained during mastectomy and were then sent to the Division of Pathomorphology and Forensic Veterinary Medicine at the Wroclaw University of Environmental and Life Sciences. Molecular tests were carried out on frozen fragments taken from 16 malignant mammary cancers in bitches.
Hematoxylin and eosin staining. The collected tumour samples were fixed in a $4 \%$ buffered formalin solution for $24 \mathrm{~h}$, were then embedded in paraffin blocks and cut into $4-\mu \mathrm{m}$ thick sections, which were stained with hematoxylin and eosin (H\&E). The histological evaluation of the microscopic preparations was made on the basis of the current classification, according to Goldschmidt et al., (6) while the histological grade (G-Grading) of tumours was determined according to the scale of Peña et al. (36).

Immunohistochemistry. Immunohistochemical (ICH) reactions were performed in 4- $\mu \mathrm{m}$ thick paraffin sections using Autostainer Link48 (Dako, Glostrup, Denmark). First, deparaffinization, rehydration and antigen retrieval were performed using the EnVision FLEX Target Retrieval Solution (Dako) $\left(97^{\circ} \mathrm{C}\right.$ for $20 \mathrm{~min}$; $\mathrm{pH}=6$ for $\mathrm{Ki}-67$ and $\mathrm{pH}=9$ for D2-40, $\alpha$-SMA and Vimentin) in Dako PT-Link. The activity of endogenous peroxidase was blocked by a 5 -minute incubation with the EnVision FLEX Peroxidase-Blocking Reagent (Dako). Subsequently, primary murine monoclonal antibodies directed against the Ki-67 clone MIB-1 (RTU, IR626, Dako), D240 (RTU, IR072, Dako), HER-2 (1:200, A0485, Dako), $\alpha$ Smooth Muscle Actin (RTU, IR611, Dako) and Vimentin (RTU, IR630, Dako) were applied for $20 \mathrm{~min}$. Then the slides were incubated with EnVision FLEX/ HRP for 20 min. 3,3'-diaminobenzidine (DAB, Dako) was used as the peroxidase substrate and the sections were incubated for 10 minutes. Finally, all sections were counterstained with EnVision FLEX Hematoxylin (Dako) for 5 min. Following dehydration in graded ethanol concentrations $(70 \%, 96 \%, 99.8 \%)$ and in xylene, the slides were sealed with coverslips in Dako Mounting Medium (Dako).

Assessment of HE and IHC. The examined tumours were subjected to computer-aided image analysis using a computer coupled with an Olympus BX53 optical microscope (Olympus Life Science, Japan) equipped with a Color View IIIu digital camera (Olympus Life Science) at $400 \times$ magnification. 
in vivo $34: 213-223(2020)$

Table III. Assessment of podoplanin (PDPN) expression in cancer-associated fibroblasts (CAFs) and cancer cells depending on histopathologic diagnosis.

\begin{tabular}{|c|c|c|c|c|c|c|}
\hline & $\begin{array}{l}\text { Histological } \\
\text { type }\end{array}$ & $\mathrm{N}$ & $\begin{array}{l}\text { Expression of } \\
\text { PDPN in CAFs } \\
\text { (n) }\end{array}$ & $\begin{array}{l}\text { Median (range } \\
\text { of IRS scale) }\end{array}$ & $\begin{array}{c}\text { Expression of } \\
\text { PDPN in cancer cells } \\
\text { (n) }\end{array}$ & $\begin{array}{c}\text { Median (range } \\
\text { of IRS scale) }\end{array}$ \\
\hline \multirow[t]{5}{*}{$\begin{array}{l}\text { Malignant tumour, } \mathrm{n}(\%) \\
\mathrm{n}=61\end{array}$} & $\begin{array}{l}\text { Simple } \\
\text { tubulopapillary } \\
\text { carcinoma }\end{array}$ & 22 & 3 & $6(1-9)$ & 11 & $3(1-9)$ \\
\hline & $\begin{array}{l}\text { Simple cystic } \\
\text { carcinoma }\end{array}$ & 12 & 6 & $1.5(1-8)$ & 6 & $2.5(1-6)$ \\
\hline & Solid carcinoma & 11 & 4 & $1.5(1-2)$ & 5 & $2(1-4)$ \\
\hline & Mixed carcinoma & 8 & 0 & 0 & 2 & $5.5(2-9)$ \\
\hline & Complex carcinoma & 8 & 1 & $1(1)$ & 2 & $5.5(2-9)$ \\
\hline $\begin{array}{l}\text { Benign tumour, } \mathrm{n}(\%) \\
\mathrm{n}=21\end{array}$ & Simple adenoma & 21 & 0 & 0 & 7 & $1(1-4)$ \\
\hline
\end{tabular}

The assessment of podoplanin expression in CAFs and tumour cells was made on the basis of a modified scale compatible with Remmele and Stegner immunoreactive score (IRS) (37), shown in Table I. The final outcome takes into account the product of both the percentage of positive cells (A) and the intensity of expression (B) and its value ranges from 1 to 12 points, according to the following scale: i) no reaction $=0$ points $(-)$, ii) light reaction $=1-2$ points $(+)$, iii) moderate reaction $=3-4$ points $(++)$, iv) intense reaction $=6-12$ points $(+++)$.

The location of CAFs was verified and confirmed by colocalization of D2-40, $\alpha$ SMA and vimentin staining on serial sections.

The Ki-67 assessment was performed using a scale that included the percentage of cell nuclei with a positive reaction: i) $0-5 \%$ no reaction $(-)$, ii) $6-25 \%$ weak reaction $(+)$, iii) $26-50 \%$ moderate reaction (++), iv) above $50 \%$ cells - intense reaction (+++) (7).

The expression intensity of HER 2 receptor was assessed using a scale that took into account the percentage of tumour cells showing a positive membrane reaction: i) no staining or staining in less than $10 \%$ of the tumour cells (-), ii) very weak and incomplete membrane staining of more than $10 \%$ of the tumour cells $(+)$, iii) light or moderate intensity membrane reaction in more than $10 \%$ of tumour cells or complete and intense membrane reaction in less than $10 \%$ of tumour cells $(++)$, and iv) complete and strong membrane staining of more than $10 \%$ of tumour cells $(+++)$. HER 2 expression results of $(-)$ and $(+)$ were classified as negative, while $(++)$ and $(+++)$ cases were considered positive (8).

$P C R$. Total RNA was isolated from frozen fragments of the tissue using the RNeasy Mini Kit (Qiagen, Milden, Germany) in line with the manufacturer's recommended procedures. Reverse transcription reactions were performed using the High-Capacity cDNA Reverse Transcription kit (Applied Biosystems, Foster City, CA, USA). Relative mRNA expression of PDPN was evaluated by real-time PCR, using the 7500 Real-time PCR system and the iTag Universal Probes Supermix (Bio-Rad, Hercules, CA, USA). Beta-actin was used as the reference gene. For the reactions, the following sets of primers and TaqMan probes were used: i) Cf02628973_m1 for PDPN and ii) Cf04931159_m1 for $\beta$-actin (Applied Biosystems). All reactions were performed in triplicates under the following conditions: i) initial denaturation at $94^{\circ} \mathrm{C}$ for $10 \mathrm{~min}$, ii) 40 cycles of denaturation at $94^{\circ} \mathrm{C}$ for $15 \mathrm{~s}$, followed by iii) annealing and elongation at $60^{\circ} \mathrm{C}$ for $60 \mathrm{~s}$.

Statistical analysis. Statistical analysis was performed using the StatisticaPL 12.0 program (StatSoft, Poland). Data normality was analyzed using the W Shapiro-Wilk test. The analysis of differences between groups was performed using the Kruskal-Wallis test. The correlation analysis of the obtained results was carried out using the Spearman's correlation test. Differences between results of different grades tumours as well as for adenomas and cancers were analyzed using the Mann-Whitney $U$-test and Kruskal-Wallis analysis, respectively. The significance level was assumed for $p$ Value $<0.05$.

\section{Results}

Age and breed of the patients. Our statistical analysis showed no relationship of podoplanin expression in CAFs and cancer cells with ageing $(p>0.05)$ or the breed of the animal $(p>0.05)$.

Immunohistochemistry. Expression of PDPN was found in both stromal (CAFs) and cancer cells in mammary tumours in bitches, and the results are shown in Table II. Statistical analysis showed no significant relationship between the PDPN expression levels in stromal cells (CAFs) and in cancer cells $(p>0.05)$. It should be noted, however, that in 10 out of 14 cases of cancers in which a positive PDPN reaction was observed in CAFs (CAFs+), a positive cytoplasmic reaction of PDPN in cancer cells was also reported. Moreover, we assessed the expression of cell proliferative antigen $\mathrm{Ki}-67$ and HER2 receptor for mammary carcinomas and mammary adenomas, and found that $\mathrm{Ki}-67$ expression in cancer cells in $90 \%$ malignant tumours and $5 \%$ benign tumours, expression of HER2 was observed in $82 \%$ malignant tumours and $71 \%$ benign tumours in female dogs. The results are presented in Table II. The results regarding the histological types and tumours, 
Table IV. Assessment of podoplanin (PDPN) expression depending on the malignancy grade, expression of Ki-67 and HER2 in malignant mammary cancers in bitches.

\begin{tabular}{|c|c|c|c|c|c|c|c|}
\hline & $\mathrm{N}$ & $\begin{array}{l}\text { PDPN in CAFs } \\
(\mathrm{n})\end{array}$ & $\begin{array}{l}\text { Median (range } \\
\text { of IRS scale) }\end{array}$ & $p$-Value, $\mathrm{r}$ & $\begin{array}{l}\text { PDPN in cancer cells } \\
(\mathrm{n})\end{array}$ & $\begin{array}{c}\text { Median (range } \\
\text { of IRS scale) }\end{array}$ & $p$-Value, $\mathrm{r}$ \\
\hline Grading & & & & $<0.05, \mathrm{r}=0.37$ & & & $>0.05$ \\
\hline G1 & 30 & 4 & $1(1-2)$ & & 13 & $3(1-9)$ & \\
\hline $\mathrm{G} 2$ & 26 & 5 & $2(1-6)$ & & 9 & $4(1-9)$ & \\
\hline G3 & 5 & 5 & $2(1-9)$ & & 4 & $2.5(1-4)$ & \\
\hline $\mathrm{Ki}-67$ & & & & $<0.05, \mathrm{r}=0.37$ & & & $>0.05$ \\
\hline None (-) & 6 & 0 & 0 & & 3 & $2(2-9)$ & \\
\hline Weak (+) & 15 & 1 & $1(1)$ & & 4 & $2(2-9)$ & \\
\hline Moderate $(++)$ & 22 & 6 & $1(1)$ & & 12 & $4(2-9)$ & \\
\hline Intense $(+++)$ & 18 & 7 & $2(2-9)$ & & 7 & $2(1-4)$ & \\
\hline HER 2 & & & & $>0.05$ & & & $<0.05 ; \mathrm{r}=0.28$ \\
\hline None (-) & 4 & 0 & 0 & & 0 & 0 & \\
\hline Weak (+) & 7 & 1 & $1(1)$ & & 3 & $4(2-9)$ & \\
\hline Moderate (++) & 10 & 5 & $2(1-6)$ & & 2 & $1(1)$ & \\
\hline Intense $(+++)$ & 40 & 8 & $1.5(1-9)$ & & 21 & $3(1-9)$ & \\
\hline
\end{tabular}

r, Correlation value.

and in particular the malignancy grades, are shown in Tables III and IV.

Expression of PDPN in CAFs. Expression of PDPN in CAFs was found in $22.9 \%(n=14)$ of mammary tumours, which was confirmed by the co-localization of vimentin and $\alpha$-SMA in serial sections (Figure 1). The intensity of PDPN expression in CAFs ranged from 1 to 9 points on the IRS scale, where $79 \%$ of CAFs+ tumours showed a low level of expression of PDPN at the level of 1-2 points, and $21 \%$ of CAFs+ tumours at a high level rated at 6-9 points (Table II, Figure 2). There was no expression of PDPN in CAFs in any of the examined cases of mammary adenomas. A statistically significant difference was demonstrated between PDPN expression in CAFs in mammary carcinomas and mammary adenomas $(p=0.02)$ (Figure 3). PDPN expression level in CAFs was significantly higher in malignant tumours than benign tumours. The results showing PDPN expression in CAFs, depending on the histopathological diagnosis, are presented in Table III. Statistical analysis did not show significant differences at the level of PDPN expression in CAFs irrespective of the histopathological type of tumour $(p>0.05)$.

The results of the intensity of PDPN expression in CAFs depending on the histological grade of the tumour are presented in Table IV. In all tumours assessed as G3, strong PDPN expression in CAFs was observed. In addition, G3 tumours were characterized by higher PDPN expression values according to the IRS scale compared to $\mathrm{G} 2(p=0.008)$ and $\mathrm{G} 1$ tumours $(p=0.003)$. The statistical analysis showed a positive correlation between PDPN expression in CAFs and the degree of histological malignancy $(\mathrm{G})$ in the examined mammary gland tumours $(p<0.05, \mathrm{r}=0.37)$ (Table IV).
Using the IHC methods, the intensity degree of the expression of Ki-67 antigen and HER2 receptor was assessed. A positive correlation was found between PDPN expression in CAFs and expression of the Ki-67 marker in cancer cells in mammary tumours $(p<0.05, \mathrm{r}=0.37)$ (Table IV). Higher PDPN expression intensity in CAFs was also observed in HER2-positive tumours compared to HER2negative tumours. The statistical analysis showed no relationship between HER2 receptor expression in cancer cells and PDPN expression in CAFs ( $p>0.05)$ (Table IV).

Expression of podoplanin in cancer cells. The expression of PDPN in cancer cells was observed in $42.6 \%(n=26)$ of the cases of malignant tumours (carcinomas) studied, and the value of results was 1-9 points according to the IRS scale, of which i) $42 \%(n=11)$ showed a weak reaction (1-2 points), ii) $31 \%(n=8)$ a moderate reaction (3-5 points) and iii) $27 \%$ $(n=7)$ a strong reaction (6-9 points). The results are shown in Table II (Figure 4). For benign tumours, PDPN expression in cancer cells was also observed in $33 \%(n=7)$ of lesions, of which PDPN expression was weak, i) 1 point according to the IRS scale for $86 \%$ of the examined benign lesions $(n=6)$ studied and ii) at a moderate level of 4 points according to the IRS scale for $14 \%$ of adenomas $(n=1)$. The statistical analysis did not show a significant difference in PDPN expression in cancer cells between carcinomas and adenomas $(p=0.2)$ (Figure 3$)$.

The assessment of PDPN expression intensity in cancer cells from the individual histological diagnoses is presented in Table III. The statistical analysis did not show any significant differences at the level of PDPN expression in cancer cells depending on the histopathological type of 
$(+)$ Solid carcinoma



$(+++)$ Simple cystic carcinoma

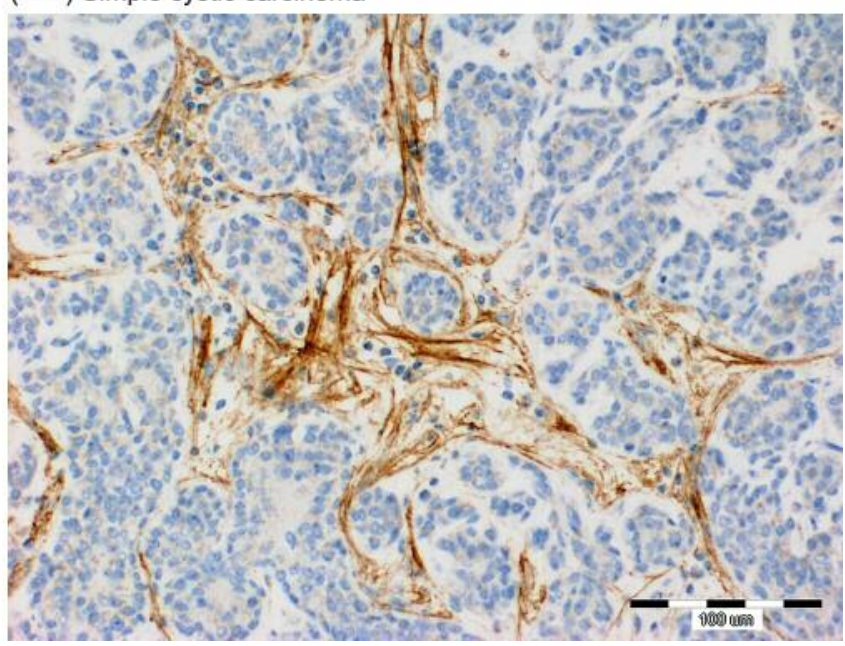

Figure 2. Expression of podoplanin (PDPN) in cancer-associated fibroblasts (CAFs) in mammary cancers in female dogs (different degrees of Remmele). Scale bar=100 $\mu \mathrm{m}$.

tumours $(p>0.05)$. A summary of the intensity of PDPN expression in cancer cells and the relationship between the degree of tumour malignancy $(\mathrm{G})$ and the expression of $\mathrm{Ki}$ 67, HER2 in malignant tumours are presented in Table IV. No statistically significant correlation between PDPN expression level in cancer cells and the degree of histological malignancy $(\mathrm{G})(p>0.05)$, the Ki- 67 expression $(p>0.05)$ was found. The statistical analysis showed a positive correlation of PDPN expression in cancer cells and HER2 receptor expression in mammary tumours $(p<0.05, \mathrm{r}=0.28)$ (Table IV).

Real-time PCR. Expression of the PDPN gene at the mRNA level was found in $100 \%(n=16)$ of the analyzed mammary tumours. The results are presented in Figure 5. The statistical analysis did not show a significant relationship between PDPN expression at the mRNA level and the degree of histological malignancy of the tumours $(p>0.05)$. However, a higher PDPN expression level was observed at the mRNA level in G2 and G3 tumours in relation to G1 tumours (Table IV).

\section{Discussion}

In recent years, we have seen a visible increase in the number of diagnosed mammary tumours in female dogs. This fact is confirmed by numerous statistical data, where, for example, in Poland in Lower Silesia in the years 20052008, 331 cases of mammary tumours were recorded, which constitute on average 83 cases per year (of which about $71.2 \%$ were classified as malignant forms). In 2009-2011, many more such tumours were registered, i.e. 705 cases, representing 235 cases per year on average (of which $75.6 \%$ are malignant) (2, 3). In the following years (2012-2013), 640 cases were recorded, i.e. 320 cases per year (of which $83 \%$ were malignant) (5). The number of registered breast cancer cases in women has also been increasing in recent years. According to data collected and published by the Lower Silesian Oncology Center in Wroclaw, the most frequently diagnosed cancers in women are also malignant tumours of the mammary gland constituting consecutively: i) in year 2010-1331 cases, ii) in 2012-1401 cases, iii) in 2014-1421 cases, and iv) in 2016-1669 cases among all diagnosed cancers in women (38-41). Statistics show that both mammary tumours in female dogs and breast cancers in women constitute a high percentage of diagnosed cancerous lesions. This information may also indicate an upward trend in the formation of new oncological lesions in this organ in both animals and humans. In order to better understand the mechanism of carcinogenesis, new markers are constantly being sought, which may also be useful for the diagnosis of oncological lesions, as well as for predicting the course of the disease, prognosis and treatment.

Both epithelial and stromal cells may undergo carcinogenesis in the mammary gland. At the same time, CAFs, which are part of the stroma, have been linked to the oncogenesis process in humans (13-15, 20, 42). A recent report by Król et al., has also confirmed the presence of CAFs in mammary tumours of female dogs due to the isolation of the carcinoma-associated fibroblast cell line (25). Moreover, this group has reported that CAFs promote angiogenesis and adhesion cells and participate in signaling pathways associated with epithelial-mesenchymal transition (EMT), thereby enhancing the tumour invasive properties and increasing their potential for metastasis in 



Figure 3. Differences between podoplanin (PDPN) expression in cancer-associated fibroblasts $(C A F s)(p=0.02, p<0.05)$ and in $33 \%$ in cancer cells $(p=0.2 ; p>0.05)$ in mammary cancers and adenomas in bitches. PDPN expression level in CAFs was significantly higher in malignant tumours than benign tumours. The expression of PDPN in cancer cells was observed in $42.6 \%$ in carcinomas and in $33 \%$ in adenomas.

mammary tumours (25). This information suggests that the role of CAFs in the dog's body can be very similar to the function of these cells in the human body.

There are few reports describing PDPN expression in canine cancers. Sleeckx N et al., have performed IHC tests with the use of PDPN. Nevertheless, the authors have not observed PDPN expression in any of the examined cases of mammary tumours in bitches (43). It is worth noting, however, that the study cohort in that report was only 5 malignant and 5 benign tumours. Due to the fact that in our results only about $23 \%$ of cases of malignant lesions demonstrated PDPN expression in CAFs, the lack of PDPN expression in CAFs in the studies by Sleeckx $\mathrm{N}$ et al. may down to the small number of examined tumours.

PDPN is one of the most important proteins that allow the immunohistochemical location of CAFs, and, moreover, the level of the expression of this marker may has a prognostic value for the oncological patient $(12-15,20,27,33)$. The expression of PDPN in CAFs is mainly observed in malignant tumours, including invasive pulmonary adenomas, esophageal adenocarcinomas and invasive ductal carcinomas (IDCs), but it is not expressed in benign tumours $(12,14,20$, $27,33)$. Similar to the study results described above, our studies showed the expression of PDPN in CAFs in only about $23 \%$ of cancers, with no expression in mammary adenomas in bitches. Moreover, in our studies we obtained a statistically significant difference in PDPN expression in CAFs between mammary carcinomas and adenomas in bitches. Demonstration of PDPN expression in CAFs in malignant neoplasms could potentially link its function with the process of carcinogenesis.
Importantly, we also found a positive correlation between PDPN expression in CAFs with factors that may be of significance in the prognosis and survival time in bitches with mammary tumours, e.g. a higher degree of histological malignancy of the tumour. This result is similar to the results of studies conducted on IDC in women, which have also showed a positive correlation between the expression of PDPN in CAFs in tumours and the degree of histological malignancy $(G)(14,20,27)$. Moreover, we have obtained a positive correlation between PDPN expression in CAFs and the intensity of Ki-67 expression in mammary tumours in bitches. Similar results have been obtained by Pula et al., who found a positive correlation between the intensity of PDPN expression and the Ki-67 protein in IDC in women (14). Both the histological grade and the Ki-67 protein are commonly used as prognostic markers in cancer patients in human medicine but also increasingly in veterinary medicine. The demonstrated correlations may indicate the role of PDPN during the neoplastic process of mammary tumours in bitches as well as the important and prognostic function of the examined protein. In the future, stromal assessment may become a significant element that can determine more accurate the prognosis in bitches during the course of a neoplastic disease.

Similar to us, the co-expression of PDPN in CAFs with HER2 receptor expression has also been demonstrated in cancer cells in IDC in women (15). HER2 is an important marker used in the diagnosis of breast cancer in women, while it is more and more frequently used for IHC tests in veterinary medicine (9-11). This receptor participates in the oncogenesis processes, by affecting cancer cell migration, increasing 
(+) Simple cystic carcinoma

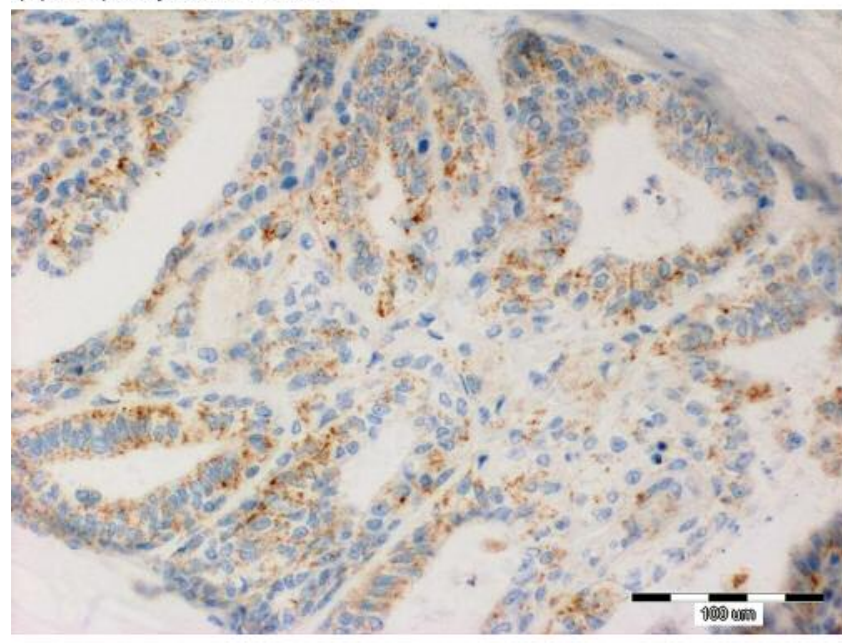

(+) Simple tubulopapillary carcinoma

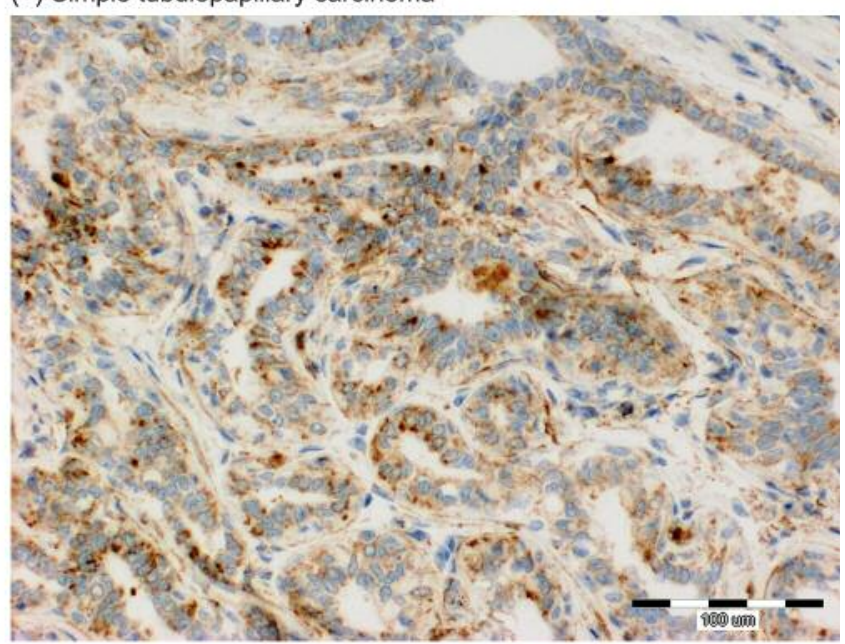

$(+++)$ Simple cystic carcinoma

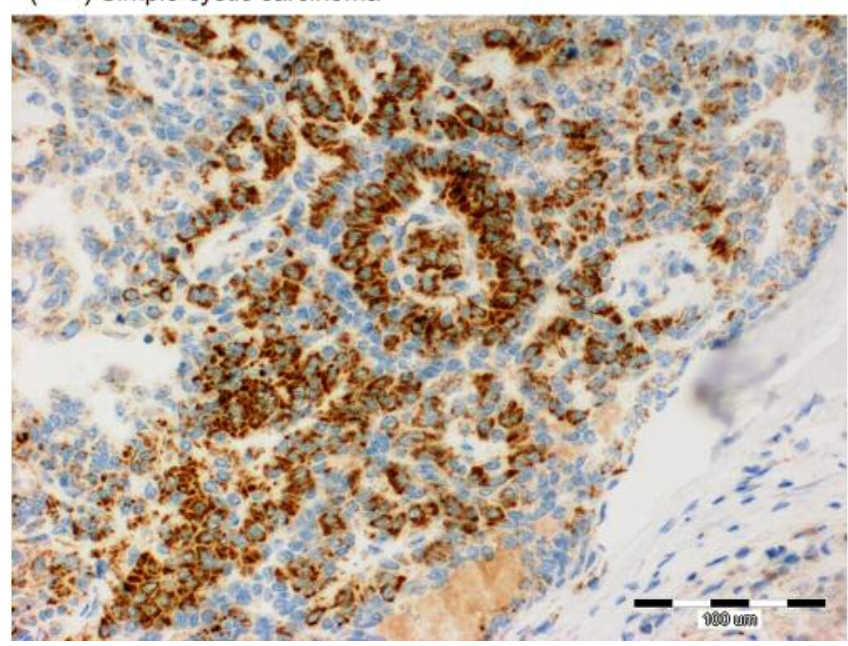

Figure 4. Expression of podoplanin (PDPN) in cancer cells in mammary cancers in bitches (different degrees of Remmele). Scale bar=100 $\mu m$.

angiogenesis, and metastasis of cancer cells $(9-11,44)$. In these published studies, there is no relationship reported between the intensity of the HER2 receptor expression and the level of PDPN expression in CAFs in mammary tumours in bitches. In our studies, we observed only slightly higher HER2 expression levels in malignant compared to benign lesions; albeit with no significant differences. Similar to us, no significant correlation has been shown betweenHER2 receptor expression and PDPN expression in CAFs in human breast cancer $(14,20)$.

Concerning the cytoplasmic localization of PDPN in cancer cells of mammary tumours in female dogs, our studies demonstrated a slightly higher percentage of tumours with PDPN expression in the cytoplasm of cancer cells' cytoplasm (42\%) compared to cells in adenomas (38\%). Moreover, higher PDPN expression levels in cancer cells have been found in mammary tumours in bitches compared to studies on breast tumours in women. In the case of breast tumours in women, PDPN expression in the cytoplasm of cancer cells has been observed in only $8 \%$ of cases (12) and $1.7 \%$ of cases (14). The difference is significantly higher $(6.3 \%)$ in the Shoppmann study (12).

Our analysis showed a positive relationship between HER2 receptor and PDPN expression in cancer cells of mammary tumours in bitches. This result indicates that PDPN may be involved in the process of epithelial cell carcinogenesis, while its expression in cancer cells probably does not have such a significant diagnostic value as in the case of CAFs.

To sum up, we are the first to find PDPN expression in CAFs using IHC, and we have confirmed the expression of PDPN in mammary tumours at the level of mRNA as well as protein. Moreover, we suppose that CAFs cells included 


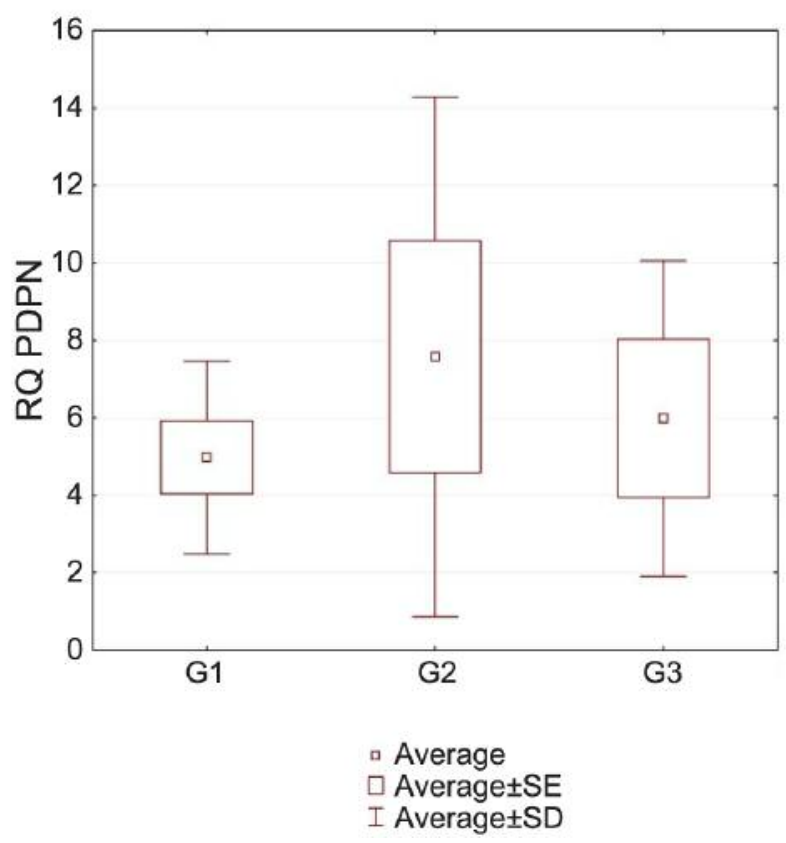

Figure 5. Levels of PDPN expression at mRNA level in mammary tumours.

in the stroma of mammary tumours can play an important role in the carcinogenesis process in bitches. The obtained test results and positive correlations between PDPN expression in CAFs and factors that may indicate an unfavorable prognosis for oncologic patients, i.e. histological grade $(\mathrm{G})$, and Ki-67 antigen expression suggest that PDPN may can be used in diagnostics during the mammary oncogenesis process in bitches, as in the case of breast cancers in women $(13-15,20,27,34)$. In addition, we suppose that in the future PDPN may be used as a diagnostic marker for the stromal cells (CAFs) of mammary tumours, and may also have prognostic significance for female dogs diagnosed with mammary tumours.

\section{Ethical Approval}

According to the Polish law, standard diagnostic procedures and studies conducted on animal tissue do not require permission from the Ethical Board.

\section{Conflicts of Interest}

The Authors declare that they have no competing interests.

\section{Authors' Contributions}

Histopathological examinations were performed by PB, RC, MN. Conceptualization and Methodology: PB, RC, MN, Data Curation PB, Methodology, Investigation and Validation: PB, KRW, AP, AK. The immunohistochemical examination, as well as the manuscript preparation were performed by $\mathrm{PB}$. The statistical analysis was performed by IJ. Writing-Original Draft Preparation: PB, Writing Review \& Editing: MPO, PD, MN. All the Authors read and approved the final manuscript.

\section{Acknowledgements}

The Authors would like to thank the supporting staff of the Department of Pathology at Wroclaw University of Environmental and Life Sciences and the Department of Histology and Embryology of Wroclaw Medical University.

\section{References}

1 Vascellari M, Capello K, Carminatoa A, Zanardelloa C, Baionib $\mathrm{E}$ and Multinelia F: Incidence of mammary tumours in the canine population living in the Veneto region (Northeastern Italy): Risk factors and similarities to human breast cancer. Prev Vet Med 126: 183-189, 2016. PMID: 26948297. DOI: 10.1016/ j.prevetmed.2016.02.008

2 Ciaputa R, Kandefer-Gola M, Nowak M and Madej JA: Prevalence of tumours in domestic animals in the lower silesia (Poland) in 2009-2011. Bull Vet Inst Pulawy 57(1): 53-59, 2015. DOI: 10.2478 /bvip-2013-0010

3 Nowak M, Madej JA, Ciaputa $R$ and Poradowski D: Manifestation of tumours in domestic animals in Lower Silesia in 2005-2008. Bull Vet Inst Pulawy 54(2): 229-236, 2010. DOI: $10.21521 / \mathrm{mw} .5637$

4 Sleeckx N, de Rooster H, Veldhuis Kroeze EJ, Van Ginneken C and Van Brantegem L: Canine Mammary Tumours, an Overview. Reprod Domest Anim 46(6): 1112-1131, 2011. PMID: 21645126. DOI: $10.1111 / \mathrm{j} .1439-0531.2011 .01816 . x$

5 Ciaputa R, Madej J, Lagodzki P, Pakuła J, Kandefer- Gola M, Janus I, Dzimira S and Nowak M: Prevalence of tumours in domestic and exotic animals in Lower Silesia between 2012 and 2013. Bull Vet Inst Pulawy 73(2): 104-110, 2017. DOI: $10.21521 / \mathrm{mw} .5637$

6 Goldschmidt M, Pena L, Rasotto R and Zappulli V: Classification and grading of canine mammary tumours. Vet Pathol 48(1): 11731, 2011. PMID: 21266722. DOI: 10.1177/0300985810393258

7 Nowak M, Madej JA, Pula B, Dziegiel P and Ciaputa R: Expression of matrix metalloproteinase 2 (MMP-2), E-cadherin and $\mathrm{Ki}-67$ in metastatic and non-metastatic canine mammary carcinomas. Ir Vet J 69: 9, 2016. PMID:27486511. DOI: 10.1186/s13620-016-0068-3

8 Wolff AC, Hammond ME, Hicks DG, Dowsett M, McShane LM, Allison KH, Allred DC, Bartlett JM, Bilous M, Fitzgibbons P, Hanna W, Jenkins RB, Mangu PB, Paik S, Perez EA, Press MF, Spears PA, Vance GH, Viale G, Hayes DF, American Society of Clinical Oncology and College of American Pathologists: Recommendations for human epidermal growth factor receptor 2 testing in breast cancer: American Society of Clinical Oncology/College of American Pathologists clinical practice guideline update. J Clin Oncol 31(31): 3997-4013, 2013. PMID: 24101045. DOI: 10.1200/JCO.2013.50.9984

9 Nowak M, Madej JA and Dzięgiel P: Correlation in the expression of HER2 and ki-67 antigen in mammary adenocarcinomas in bitches. Bull Vet Inst Pulawy 49(3): 337-342, 2005.

10 Peña L, Gama A, Goldschmidt MH Abadie J, Benazzi C, Castagnaro M, Díez L, Gärtner F, Hellmén E, Kiupel 
M, Millán Y, Miller MA, Nguyen F, Poli A, Sarli G, Zappulli V and de las Mulas JM: Canine mammary tumours: a review and consensus of standard guidelines on epithelial and myoepithelial phenotype markers, HER2, and hormone receptor assessment using immunohistochemistry. Vet Pathol 51(1): 127-145, 2014. PMID: 24227007. DOI: 10.1177/0300985813509388

11 Lohrisch C and Piccart M: An overview of HER2. Sem Oncol 28: 3-11, 2001. DOI: 10.1016/S0093-7754(01)90103-4

12 Schoppmann SF, Berghoff A, Dinhof C, Jakesz R, Gnant M, Dubsky P, Jesch B, Heinzl H and Birner P: Podoplanin-expressing cancer-associated fibroblasts are associated with poor prognosis in invasive breast cancer. Breast Cancer Res Treat 134(1): 237244, 2012. PMID: 22350732. DOI: 10.1007/s10549-012-1984-X

13 Pula B, Witkiewicz W, Dziegiel P and Podhorska-Okolow M: Significance of podoplanin expression in cancer-associated fibroblast - A comprehensive review. Int J Oncol 42(6): 18491857, 2013. PMID: 23588876. DOI: 10.3892/ijo.2013.1887

14 Pula B, Jethon A, Piotrowska A, Gomulkiewicz A, Owczarek T, Calik J, Wojnar A, Witkiewicz W, Rys J, Ugorski M, Dziegiel P and Podhorska-Okolow M: Podoplanin expression by cancerassociated fibroblasts predicts poor outcome in invasive ductal breast carcinoma. Histopathology 59(6): 1249-1260, 2011. PMID: 22175904. DOI: 10.1111/j.1365-2559.2011.04060.x

15 Pula B, Wojnar A, Werynska B, Ambicka A, Kruczak A, Witkiewicz W, Ugorski M, Podhorska-Okolow M and Dziegiel P: Impact of different tumour stroma assessment methods regarding podoplanin expression on clinical outcome in patients with invasive ductal breast carcinoma. Anticancer Res 33(4): 1447-1455, 2013. PMID: 23564785.

16 Jung YY, Lee YK and Koo JS: Expression of cancer-associated fibroblast-related proteins in adipose stroma of breast cancer. Tumour Biol 36(11): 8685-8695, 2015. PMID: 26044562. DOI: 10.1007/s13277-015-3594-9

17 Mueller L, Goumas FA, Affeldt M, Sandtner S, Gehling UM, Brilloff S, Walter J, Karnatz N, Lamszus K, Rogiers X and Broering DC: Stromal fibroblasts in colorectal liver metastases originate from resident fibroblasts and generate an inflammatory microenvironment. Am J Pathol 171(5): 1608-1618, 2007. PMID: 179165596. DOI: 10.2353/ajpath.2007.060661

18 Zeisberg EM, Potenta S, Xie L, Zeisberg M and Kalluri R: Discovery of endothelial to mesenchymal transition as a source for carcinoma-associated fibroblasts. Cancer Res 67(21): 10123-10128, 2007. PMID: 17974953. DOI: 10.1158/0008-5472.CAN-07-3127

19 Beuer M, Su G, Casper C, He R, Rehreuer W and Friedl A: Heterogeneity of gene expression in stromal fibroblasts of human breast carcinomas and normal breast. Oncogene 29(12): 1732-1740, 2010. PMID: 20062080. DOI: 10.1038/onc.2009.463

20 Pula B, Wojnar A, Witkiewicz W, Dzięgiel P and PodhoroskaOkolow M: Podoplanin expression in cancer-associated fibroblasts correlates with VEGF-C expression in cancer cells of invasive ductal breast carcinoma. Neoplasma 60(5): 516-524, 2013. PMID: 23790170. DOI: 10.4149/neo_2013_067

21 Allen M and Louise Jones J: Jekyll and Hyde: The role of the microenvironment on the progression of cancer. J Pathol 223(2): 162-176, 2011. PMID: 21125673. DOI: 10.1002/path.2803

22 Hasebe T, Sasaki S, Imoto S and Ochiai A: Proliferative activity of intratumoural fibroblast is closely correlated with lymph node and distant organ metastases of invasive ductal carcinoma of the breast. Am J Pathol 156(5): 1701-1710, 2000. PMID: 10793081. DOI: 10.1016/S0002-9440(10)65041-9
23 Cheng N, Bhowmick NA, Chytil A, Gorska A, Brown K, Muraoka R, Arteaga C, Neilson E, Hayward S and Moses H: Loss of TGF-beta type II receptor in fibroblasts promotes mammary carcinoma growth and invasion through upregulation of TGF-alpha-, MSP- and HGF-mediated signaling networks. Oncogene 24(32): 5053-5068, 2005. PMID: 15856015. DOI: $10.1038 /$ sj.onc. 1208685

24 Ito S, Ishii G, Hoshino A, Neri S, Kuwata T, Higashi M, Nagai $\mathrm{K}$ and Ochiai: Tumour promoting effect of podoplanin-positive fibroblasts is mediated by enhanced RhoA activity. Biochem and Biophys Res Commun 422(1): 194-199, 2012. PMID: 22575513. DOI: $10.1016 /$ j.bbrc.2012.04.158

25 Król M, Pawłowski KM, Szyszko K, Maciejewski H, Dolka I, Manuali E, Jank M and Motyl T: The gene expression profiles of canine mammary cancer cells grown with carcinoma-associated fibroblasts (CAFs) as a co-culture in vitro. BMC Vet Res 8: 35 , 2012. PMID: 22453032. DOI: 10.1186/1746-6148-8-35

26 Ugorski M, Dziegiel P and Suchanski J: Podoplanin - a small glycoprotein with many faces. Am J Cancer Res 6(2): 370-386, 2016. PMID: 27186410

27 Schoppmann SF, Jesch B, Reigler MF, Maroske F, Schwameis $\mathrm{K}$, Jomrich $\mathrm{G}$ and Birner P: Podoplanin-expressing cancerassociated fibroblasts are associated with unfavourable prognosis in adenocarcinoma of the esophagus. Clin Exp Metastasis 30(4): 441-446, 2012. PMID: 22350732. DOI: 10.1007/s10585-0129549-2

28 Suchanski J, Tejchman A, Zacharski M, Piotrowska A, Grzegrzolka J, Chodaczek G, Nowinska K, Rys J, Dziegiel P, Kieda $\mathrm{C}$ and Ugorski M: Podoplanin increases the migration of human fibroblasts and affects the endothelial cell network formation: A possible role for cancer-associated fibroblasts in breast cancer progression. PLoS One 12(9): e0184970, 2017. PMID: 28938000. DOI: 10.1371/journal.pone.0184970

29 Nose K, Saito H and Kuroki T: Isolation of gene sequence induced later by tumour- promoting 12-O-tetradecanoylphorbol13-acetate in mouse osteoblastic calls (MC3T3-E1) and expressed constitutively in ras-transformed cells. Cell Growth Differ 1(11): 511-518, 1990. PMID: 2088477.

30 Schacht V, Dadras SS, Johnson LA, Jackson DG, Hong YK and Detmar M: Up-regulation of the lymphatic marker podoplanin, a mucin-type transmembrane glycoprotein, in human squamous cell carcinomas and germ cell tumours. Am J Pathol 166(3): 913-921, 2005. PMID: 15743802. DOI: 10.1016/S0002-9440(10)62311-5

31 Breiteneder-Geleff S, Soleiman A, Kowalski H, Horvat R, Amann G, Kriehuber E, Diem K, Weninger W, Tschachler E, Alitalo K and Kerjaschki D: Angiosarcomas express mixed endothelial phenotypes of blood and lymphatic capillaries: Podoplanin as a specific marker for lymphatic endothelium. Am J Pathol 154(2): 385-394, 1999. PMID: 10027397. DOI: 10.1016/S0002-9440(10)65285-6

32 Breiteneder-Geleff S, Matsui K, Soleiman A, Meraner P, Poczewski H, Kalt R, Schaffner $G$ and Kerjaschki D: Podoplanin, novel 43-kd membrane protein of glomerular epithelial cells, is down-regulated in puromycin nephrosis. Am J Pathol 151(4): 1141-1152, 1997. PMID: 9327748.

33 Kawase A, Ishii G, Nagai K, Ito T, Nagano T, Murata Y, Hishida T, Nishimura M, Yoshida J, Suzuki K and Ochiai A: Podoplanin expression by cancer associated fibroblasts predicts poor prognosis of lung adenocarcinoma. Int J Cancer 123(5): 10531059, 2008. PMID: 18546264. DOI: 10.1002/ijc.23611 
34 Kanner WA, Galgano MT and Atkins KA: Podoplanin expression in basal and myoepithelial cells: Utility and potential pitfalls. Appl Immunohistochem Mol Morphol 18(3): 226-230, 2010. PMID: 20042851. DOI: 10.1097/PAI.0b013e3181c65141

35 Queiroga FL, Raposo T, Carvallho MI, Prada J and Pires I: Canine mammary tumours as a model to study human breast cancer: most recent findings. In Vivo 25(3): 455-465, 2011. PMID: 21576423.

36 Clemente M, Perez-Alenza MD, Illera JC and Pena L: Histologic, immunologic and ultrastructural description of vasculogenic mimicry in canine mammary cancer. Vet Pathol 47(2): 265-274, 2010. PMID: 20106772. DOI: 10.1177/ 0300985809353167

37 Remmele W and Stegner HE: Recommendation for uniform definition of an immunoreactive score (IRS) for immunohistochemical estrogen receptor detection (ER-ICA) in breast cancer tissue. Pathologe 8(3): 138-140, 1987. PMID: 3303008.

38 Błaszczyk J, Jagas M and Hudziec P: Nowotwory złośliwe w woj. dolnośląskim w roku, 2010. Wroclaw, 2012 (Polish). Available at: http://www.dco.com.pl/files/epidemiologia/BIUL2010.pdf

39 Błaszczyk J, Jagas M and Hudziec P: Nowotwory złośliwe w woj. dolnośląskim w roku, 2012. Wroclaw, 2014 (Polish). Available at: http://www.dco.com.pl/files/epidemiologia/BIUL2012.pdf

40 Błaszczyk J, Jagas M and Hudziec P: Nowotwory złośliwe w woj. dolnośląskim w roku, 2014. Wroclaw, 2016 (Polish). Available at: http://www.dco.com.pl/wp-content/uploads/2015/06/ Biul_2014.pdf
41 Błaszczyk J, Jagas M, Hudziec P: Nowotwory złośliwe w woj. dolnośląskim w roku, 2016. Wroclaw, 2018 (Polish). Available at: https://www.dco.com.pl/wp-content/uploads/2018/12/Biul_ 2016.pdf

42 Desmouliere A, Guyot C and Gabbiani G: The stroma reaction myofibroblast: a key player in the control of tumour cell behavior. Int J Dev Biol 48(5-6): 509-517, 2004. PMID: 15349825. DOI: $10.1387 / \mathrm{ijdb} .041802 \mathrm{ad}$

43 Sleeckx N, Brantegem LV, Fransen E, Van den Eynden G, Casteleyn C, Veldhuis Kroeze E and Van Ginneken C: Evaluation of immunohistochemical markers of lymphatic and blood vessels in canine mammary tumours. J Comp Pathol 148(4): 307-317, 2013. PMID: 23123127. DOI: 10.1016/j.jcpa. 2012.09.007

44 Huang F, Shi Q, Li Y, Xu L, Xu C, Chen F, Wang H, Liao H, Chang Z, Liu F, Zhang XH, Feng XH, Han JJ, Luo S and Chen YG: HER2/EGFR-AKT signaling switches TGF $\beta$ from inhibiting cell proliferation to promoting cell migration in breast cancer. Cancer Res 78(21): 6073-6085, 2018. PMID: 30171053. DOI: $10.1158 / 0008-5472 . C A N-18-0136$

Received October 12, 2019

Revised November 4, 2019

Accepted November 7, 2019 